\title{
Acutely Ruptured Intracranial Aneurysms Treated with Flow-Diverter Stents: A Systematic Review and Meta-Analysis
}

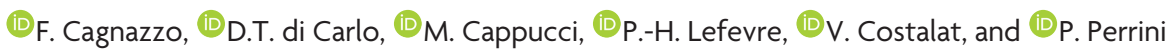

\begin{abstract}
BACKGROUND: The implantation of flow-diverter stents for the treatment of ruptured intracranial aneurysms required further investigation.

PURPOSE: Our aim was to analyze the outcomes after flow diversion of ruptured intracranial aneurysms.

DATA SOURCES: A systematic search of 3 databases was performed for studies published from 2006 to 2018.

STUDY SELECTION: According to the Preferred Reporting Items for Systematic Reviews and Meta-Analyses guidelines, we included studies (from 2010 to 2018) reporting acutely ruptured intracranial aneurysms treated with flow diversion.

DATA ANALYSIS: Random-effects meta-analysis was used to pool the following: aneurysm occlusion rate, complications, rebleeding, and factors influencing the studied outcomes.

DATA SYNTHESIS: We included 20 studies evaluating 223 patients with acutely ruptured intracranial aneurysms treated with flowdiverter stents. Immediate angiographic occlusion was obtained in $32 \%\left(29 / 86 ; 95 \% \mathrm{Cl}, 15.4 \%-48 \%\right.$; $\left.I^{2}=79.6 \%\right)$ of aneurysms, whereas long-term complete/near-complete aneurysm occlusion was $88.9 \%\left(162 / 189 ; 95 \% \mathrm{Cl}, 84 \%-93.5 \%\right.$; $\left.\mathrm{I}^{2}=20.9 \%\right)$ (mean radiologic follow-up of 9.6 months). The treatment-related complication rate was $17.8 \%\left(42 / 223 ; 95 \% \mathrm{Cl}, 11 \%-24 \% ; \mathrm{I}^{2}=52.6 \%\right)$. Complications were higher in the posterior circulation $\left(16 / 72=27 \%\right.$; $95 \% \mathrm{Cl}, 14 \%-40 \% ; I^{2}=66 \%$ versus $\left.18 / 149=11.7 \% ; 95 \% \mathrm{Cl}, 7 \%-16 \% ; I^{2}=0 \%\right)(P=.004)$ and after treatment with multiple stents $\left(14 / 52=26 \% ; 95 \% \mathrm{Cl}, 14 \%-45 \% ; I^{2}=59 \%\right)$ compared with a single stent $\left(20 / 141=10 \% ; 95 \% \mathrm{Cl}, 5 \%-15 \% ; I^{2}=\right.$ $0 \%)(P=.004)$. Aneurysm rebleeding after treatment was $4 \%\left(5 / 223 ; 95 \% \mathrm{Cl}, 1.8 \%-7 \% ; I^{2}=0 \%\right)$ and was higher in the first 72 hours.
\end{abstract}

LIMITATIONS: Small and retrospective series.

CONCLUSIONS: Flow-diversion treatment of ruptured intracranial aneurysms yields a high rate of long-term angiographic occlusion with a relatively low rate of aneurysm rebleeding. However, treatment is associated with a complication rate of $18 \%$. When coiling or microsurgical clipping are not feasible strategies, anterior circulation ruptured aneurysms can be effectively treated with a flow-diversion technique, minimizing the number of stents deployed. Given the $27 \%$ rate of complications, flow diversion for ruptured posterior circulation aneurysms should be considered only in selected cases not amenable to other treatments.

ABBREVIATIONS: ASA = acetylsalicylic acid; $\mathrm{CP}=$ clopidogrel; IQR = interquartile range; PRISMA = Preferred Reporting Items for Systematic Reviews and Meta-Analyses

$F$ ow diversion is increasingly used for a variety of intracranial aneurysms, especially complex lesions difficult to treat with conventional surgical or endovascular techniques. The thin, fragile walls and poorly defined neck make blister aneurysms partic-

Received April 13, 2018; accepted after revision May 25.

From the Department of Neurosurgery (F.C., D.T.d.C., P.P.), University of Pisa, Pisa, Italy; Radiology Department (M.C.), University of Rome Sapienza, Sant'Andrea Hospital, Rome, Italy; and Neuroradiology Department (P.-H.L., V.C.), University Hospital Güi-de-Chauliac, Centre Hospitalo-Universitaire de Montpellier, Montpellier,

France.

Please address correspondence to Federico Cagnazzo, MD, Department of Neurosurgery, University of Pisa, Via Paradisa 2, 56100, Pisa, Italy; e-mail:

f.cagnazz086@gmail.com ularly challenging lesions to treat with simple coiling or clipping, with not negligible rates of intraoperative aneurysm rupture. ${ }^{1,2}$ Similarly, the lack of a true neck in the dissecting/fusiform aneurysms usually renders coiling and clipping impossible. ${ }^{3}$ In addition, embolization of wide-neck and wide-neck bifurcation aneurysms without the use of adjunctive devices is difficult because of the instability of the coil mass. The flow-diversion devices work by diverting the flow away from the aneurysm, promoting progres-

Indicates article with supplemental on-line tables.

Indicates article with supplemental on-line photos.

http://dx.doi.org/10.3174/ajnr.A5730

AJNR Am J Neuroradiol 39:1669-75 Sep 2018 www.ajnr.org 
sive intra-aneurysmal thrombosis, leading the treatment of complex lesions. ${ }^{4}$ While a growing body of evidence corroborates the efficacy and safety of flow-diversion treatment of unruptured lesions, ${ }^{5,6}$ the off-label indications of these devices are constantly extended, including acutely ruptured intracranial aneurysms. ${ }^{7-26}$

There are 2 main concerns when flow-diverter stents are used in acute SAH: 1) the management of the antiplatelet therapy (loading and maintaining dose), which is potentially associated with hemorrhagic complications, especially when additional surgical maneuvers are required (ventriculostomy or decompressive craniectomy); and 2) the prevention of aneurysm rebleeding. ${ }^{17}$ The aim of our meta-analysis was to evaluate the safety and efficacy of the implantation of flow-diverter stents in the acute phase (0-30 days) of SAH for the treatment of ruptured intracranial aneurysms. In addition, we investigated the influence of aneurysm-related factors (type of aneurysm, location, and size), technical factors (number of devices or adjunctive coiling), patientrelated factors, and the antiplatelet therapy administration on the studied outcomes.

\section{MATERIALS AND METHODS Literature Search}

A comprehensive literature search of PubMed, Ovid MEDLINE, and Ovid EMBASE was conducted for studies published from January 2006 to March 2018. The Preferred Reporting Items for Systematic Reviews and Meta-Analyses (PRISMA ${ }^{27}$ ) guidelines were followed. Key words and the detailed search strategy are reported in On-line Table 1, and the studies included in our review (from 2010 to 2018) are reported in On-line Table 2. The inclusion criteria were the following: studies reporting series with $>3$ patients with ruptured intracranial aneurysms treated with flow-diverter stents in the acute phase. Treatment in the acute phase was considered within 30 days of SAH. Exclusion criteria were the following: 1) case reports, 2) review articles, 3) studies published in languages other than English, 4) in vitro/animal studies, and 5) flow diversion after 30 days of hemorrhage. In cases of overlapping patient populations, only the series with the largest number of patients or the most detailed data were included. Two independent readers screened articles in their entirety to determine eligibility for inclusion. A third author solved discrepancies.

\section{Data Collection}

Data were extracted by 2 independent readers. A prespecified data-collection template was used for the data collection. A third author solved discrepancies about data extraction. We extracted the following: 1) occlusion rate, 2) treatment-related complications, 3) aneurysm rebleeding rate, and 4) clinical outcome. Occlusion and complication rates were analyzed on the basis of the influence of the following: 1) anterior-versus-posterior circulation aneurysms; 2) distal-versus-proximal location; 3) patient age (younger than 60 years versus older than 60 years); 4) low-grade SAH (Fisher 1-2 or Hunt and Hess 1-2 or World Federation of Neurosurgical Societies I-II) versus high-grade SAH (Fisher 3-4 or Hunt and Hess 3-5 or World Federation of Neurosurgical Societies III-V); 5) aneurysm size (saccular aneurysms small-medium-sized versus large-giant); 6) flow diverter alone versus flow diverter plus coiling; and 7) single-versus-multiple devices. Distal location was considered for lesions arising distal to the circle of Willis or located in small vessels: A2-3 segments, middle cerebral artery, posterior cerebral artery, posterior/anterior inferior cerebellar artery, and superior cerebellar artery. Complete/near-complete aneurysm occlusion was defined on the basis of the following: 1) the Raymond-Roy classification ${ }^{28}$ (class 1-2); 2) the O'Kelly-Marotta grading scale $^{29}$ (grades C-D); or 3 ) when "complete occlusion" and "neck remnant" were used in the study. Treatment-related complications were divided into the following: 1) periprocedural/early events (within 30 days) and delayed events (after 30 days); 2) transient (asymptomatic events or complete neurologic recovery) and permanent complications (symptomatic events with permanent deficits). Finally, good outcome was defined as a modified Rankin Scale score of $0-2$ or a Glasgow Outcome Score of 4-5; or good outcome was assumed if the study used terms such as "no morbidity," "good recovery," or "no symptoms."

\section{Outcomes}

The primary objectives of this meta-analysis were to define the safety (treatment-related complications, mortality rate, and neurologic outcomes) and the efficacy (aneurysm occlusion and rebleeding rates) of the flow diversion of acutely ruptured intracranial aneurysms. The secondary objectives were to define the influence of aneurysm and patient characteristics as well as the effect of the antiplatelet therapy (loading dose and maintaining dose) on the analyzed outcomes.

\section{Quality Scoring}

The Newcastle-Ottawa Scale ${ }^{30}$ was used for the quality assessment of the included studies. The detailed scale evaluation is reported in On-lines Tables 3 and 4. In general, "high-quality" studies were defined on the basis of the following: 1) the presence of a predefined study protocol, 2) defined inclusion and exclusion criteria, 3) the presence of detailed information about treatment-related outcomes, and 4) adequate clinical and radiologic follow-up (it was considered when the follow-up time was longer than the median follow-up time of the reported studies). Accordingly, a star rating of 0-9 was allocated to each study. The quality assessment was performed by 2 authors independently, and a third author solved discrepancies. Studies receiving $\geq 6$ stars were considered "high-quality."

\section{Statistical Analysis}

We estimated, from each cohort, the cumulative prevalence (percentage) and $95 \%$ confidence interval for each outcome. To assess the heterogeneity of the data, we used the Higgins index $\left(\mathrm{I}^{2}\right)$; and subsequently, the DerSimonian and Laird random-effects model was applied. The graphic representation of the meta-analysis was performed with a forest plot. To evaluate the heterogeneity and bias, we analyzed the meta-regression and funnel plot followed by the Egger linear regression test, respectively. To compare the percentages and to calculate the $P$ values, a $Z$-test for 2 proportions was used. Differences were considered significant at $P<.05$. Statistical analyses were performed with SPSS, Version 2.3 (IBM, Armonk, New York), Prometa, Version 2 (Internovi, Cesena, Italy), and OpenMeta [Analyst] (http://www.cebm. brown.edu/openmeta/). 


\section{RESULTS}

\section{Literature Review}

Studies included in our meta-analysis are summarized in On-line Table 2. The search flow diagram is shown in On-line Fig 1.

Twenty studies and 223 patients with acutely ruptured intracranial aneurysms treated with flow-diverter stents were included in our review.

\section{Quality of Studies}

Overall, 15 studies $(75 \%)^{7,8,10,12-14,16-18,21-26}$ were retrospective single-center series, 2 studies were retrospective multicentric series, ${ }^{11,15}$ and 3 articles had a prospective design. ${ }^{9,19,20}$ Two prospective articles were rated "high quality" (On-line-Table 4).

\section{Patient Population}

Overall, 223 patients/aneurysms were treated with flow-diverter stents in the setting of SAH (On-line Table 5). The mean age of patients was 53.3 years (range, 5-80 years), and the proportion of male patients was 66\% (95\% CI, 59\%-72\%). Overall, 18.8\% (42/ 223 ; 95\% CI, 14\%-24\%) of aneurysms were saccular, 34.5\% (77/ 223; 95\% CI, 28\%-40\%) were dissecting/fusiform, and $46.6 \%$ (104/223; 95\% CI, 40\%-53\%) were blister. Most of the aneurysms $(150 / 223=67 \%$; $95 \%$ CI, 60\%-73\%) were in the anterior circulation. The mean aneurysm size was $5.6 \mathrm{~mm}$ (median, $4 \mathrm{~mm}$; interquartile range [IQR], 2-7 $\mathrm{mm}$; range, $2-16 \mathrm{~mm}$ ).

\section{Treatment Characteristics}

The mean time between SAH and flow-diversion treatment was 6.7 days (median, 4 days; IQR, 3-9.6 days). Pipeline Embolization Devices (PED; Covidien, Irvine, California) were the most common stents used $(86 \% ; 95 \%$ CI, $81 \%-89 \%)$, followed by the Silk flow diverter (Balt Extrusion, Montmorency, France) (10.6\%; 95\% CI, 7.5\%-14\%), the Flow-Redirection Endoluminal Device (FRED; MicroVention, Tustin, California) (3\%; 95\% CI, 1.4\%-5\%), and the Surpass stent (Stryker Neurovascular, Kalamazoo, Michigan) $(0.4 \%$; 95\% CI, $0.1 \%-2.2 \%)$. Most patients were treated with a single stent $(75 \% ; 95 \% \mathrm{CI}, 68 \%-80 \%)$ and without adjunctive coils ( $81 \%$; 95\% CI, 75\%-85\%). The mean radiologic follow-up was 9.6 months (median, 7.5 months; IQR, 6-12 months), and the mean clinical follow-up was 7.5 months (median, 8.7 months; IQR, 6-12 months).

\section{Angiographic Outcomes}

During a mean angiographic follow-up of 9.6 months, the overall rate of complete/near-complete occlusion was $88.9 \%(162 / 189$; 95\% CI, 84\%-93.5\%; I ${ }^{2}=20.9 \%$ ). Meta-regression showed a nonsignificant variation of the effect size during the analyzed pe$\operatorname{riod}(P=.348)$, and the funnel plot followed by the Egger linear regression test excluded publication bias $(P=.058)$ (On-line Fig 2). Complete/near-complete occlusion was achieved in $79 \%(20 /$ 25; 95\% CI, 64\%-93\%; $\mathrm{I}^{2}=0 \%$ ) of saccular aneurysms, $89 \%$ (51/58; 95\% CI, 82\%-96\%; $\left.\mathrm{I}^{2}=0 \%\right)$ of dissecting/fusiform lesions, and 88\% (76/89; 95\% CI, 81\%-95\%; $\left.\mathrm{I}^{2}=26 \%\right)$ of blister aneurysms. Immediate angiographic occlusion after stent deployment was obtained in 32\% (29/86; 95\% CI, 15.4\%-48\%; $\mathrm{I}^{2}=$ $79.6 \%)$ of aneurysms: Twenty-eight percent (2/7; 95\% CI, 3\%$\left.50 \% ; \mathrm{I}^{2}=0 \%\right)$ of saccular aneurysms, $45 \%(10 / 25 ; 95 \%$ CI, $18 \%-$ $\left.91 \% ; \mathrm{I}^{2}=90 \%\right)$ of dissecting/fusiform lesions, and 35\% (17/54; $95 \%$ CI, $14 \%-56 \% ; I^{2}=77 \%$ ) of blister aneurysms were occluded immediately after flow-diversion treatment.

\section{Treatment-Related Complications}

The overall complication rate was $17.8 \%(42 / 223$; 95\% CI, 11\%$\left.24 \% ; \mathrm{I}^{2}=52.6 \%\right)($ On-line Table 6). Meta-regression showed a nonsignificant variation of the effect size during the analyzed pe$\operatorname{riod}(P=.111)$, and the funnel plot followed by the Egger linear regression test excluded publication bias $(P=.666)$ (On-line Fig $3)$. Complications were higher among saccular aneurysms (7/ $31=23 \%$; 95\% CI, 11\%-49\%; I $\left.\mathrm{I}^{2}=43 \%\right)$ compared with dissecting/fusiform $\left(11 / 69=13 \%\right.$; 95\% CI, 5\%-20\%; $\left.\mathrm{I}^{2}=9 \%\right)$ and blister aneurysms $\left(16 / 97=18 \%\right.$; 95\% CI, 8\%-27\%; $\left.\mathrm{I}^{2}=50 \%\right)$. Periprocedural/early and delayed complication rates were $16 \%$ $\left(37 / 223 ; 95 \% \mathrm{CI}, 10 \%-22 \% ; \mathrm{I}^{2}=47 \%\right)$ and $3 \%(5 / 223 ; 95 \% \mathrm{CI}$, $\left.0.9 \%-6 \% ; I^{2}=37.7 \%\right)$, respectively. The overall rates of transient and permanent complications were $9 \%(28 / 223$; $95 \%$ CI, $4 \%-$ $\left.11 \% ; \mathrm{I}^{2}=0 \%\right)$ and $7 \%\left(16 / 223 ; 95 \% \mathrm{CI}, 4 \%-11 \% ; \mathrm{I}^{2}=0 \%\right)$, respectively.

Overall, ischemic/thromboembolic and hemorrhagic events were $8 \%\left(26 / 223 ; 95 \%\right.$ CI, 4.4\%-11\%; $\left.\mathrm{I}^{2}=22 \%\right)$ and $7 \%(16 / 223$; $95 \%$ CI, 3.5\%-10\%; $\left.\mathrm{I}^{2}=0 \%\right)$, respectively. The rate of ischemic complications was $9.9 \%\left(4 / 31 ; 95 \% \mathrm{CI}, 0.5 \%-19 \%\right.$; $\left.\mathrm{I}^{2}=0 \%\right)$ among saccular aneurysms, 8.3\% (6/69; 95\% CI, 2\%-14\%; $\mathrm{I}^{2}=$ $0 \%)$ among dissecting/fusiform lesions, and 10.2\% (12/97; 95\% CI, $4.5 \%-16 \% ; \mathrm{I}^{2}=0 \%$ ) among blister aneurysms. The rate of hemorrhagic complications was $12 \%\left(3 / 31 ; 95 \%\right.$ CI, 2\%-22\%; $\mathrm{I}^{2}=$ $0 \%)$ among saccular aneurysms, $7.5 \%\left(5 / 69 ; 95 \%\right.$ CI, 2\%-13\%; $\mathrm{I}^{2}=$ $0 \%)$ among dissecting/fusiform lesions, and $6 \%(3 / 84 ; 95 \% \mathrm{CI}$, $1.2 \%-10 \% ; \mathrm{I}^{2}=0 \%$ ) among blister aneurysms. The rate of acute in-stent thrombosis was $4 \%\left(6 / 223 ; 95 \% \mathrm{CI}, 1.6 \%-6 \%\right.$; $\left.\mathrm{I}^{2}=0 \%\right)$. The incidence of aneurysm rebleeding after treatment was $4 \%$ (5/ 223; 95\% CI, 1.8\%-7\%; $\mathrm{I}^{2}=0 \%$ ): Aneurysm rerupture occurred within the first 72 hours among one 21-mm fusiform aneurysm, 2 saccular giant lesions, and two 3 - and 8-mm saccular aneurysms. The rate of rebleeding after treatment among the anterior and posterior circulation aneurysms was 4.6\% (4/150; 95\% CI, 1.3\%-7.4\%; $\mathrm{I}^{2}=$ $0 \%)$ and $3 \%\left(1 / 73 ; 95 \% \mathrm{CI}, 1.7 \%-12 \% ; \mathrm{I}^{2}=0 \%\right)$, respectively $(P=$ $.56)$.

Treatment-related mortality was 4.5\% (6/223; 95\% CI, 2\%$\left.7 \% ; \mathrm{I}^{2}=0 \%\right)$, and the rate of good neurologic outcome was $83 \%$ (169/210; 95\% CI, 76\%-89\%; I²=0\%).

\section{Factors Related to Aneurysm Occlusion}

Overall, the occlusion rate was comparable among anterior-versus-posterior circulation aneurysms $(P=.27)$, proximal-versusdistally located aneurysms $(P=.28)$, low-versus-high-grade SAH $(P=.2)$, small-medium-sized versus large-giant aneurysms $(P=$ .6), flow diverter alone versus flow diverter plus coiling $(P=$ .12 ), and single-versus-multiple stents $(P=.61)$ (On-line Table 7). Patients younger than 60 years of age had a statistically significant higher rate of occlusion $(105 / 120=90 \%$; $95 \%$ CI, $85 \%-95 \%$; $\mathrm{I}^{2}=0 \%$ ) compared with older patients (older than 60 years $)\left(43 / 52=76 \% ; 95 \%\right.$ CI, $\left.64 \%-88 \% ; I^{2}=49 \%\right)(P=$ $.01)$. 


\section{Factors Related to Complications after Treatment}

The complication rate was higher for ruptured aneurysms located in the posterior circulation $(16 / 72=27 \%$; $95 \% \mathrm{CI}, 14 \%-40 \%$; $\left.\mathrm{I}^{2}=66 \%\right)$ compared with the anterior circulation $(18 / 149=$ 11.7\%; 95\% CI, 7\%-16\%; $\left.\mathrm{I}^{2}=0 \%\right)(P=.004)$ (On-line Table 7). In addition, complications were higher after treatment with multiple flow diverters $\left(14 / 52=26 \% ; 95 \% \mathrm{CI}, 14 \%-45 \% ; \mathrm{I}^{2}=59 \%\right)$ compared with a single stent $(20 / 141=10 \%$; $95 \%$ CI, $5 \%-15 \%$; $\left.\mathrm{I}^{2}=0 \%\right)(P=.004)$. There was no statistically significant difference in complication rates in relation to aneurysm location, patient age, aneurysm size, and flow diverter alone versus flow diverter plus coiling.

\section{Relationship between the Timing of Flow Diversion and Treatment-Related Outcomes}

Flow diversion within and after 72 hours of SAH allowed comparable rates of aneurysm occlusion (50/61 = 85\%; 95\% CI, 7\%$93 \% ; I^{2}=0 \%$ versus $64 / 70=89 \%$; $95 \%$ CI, $\left.8 \%-9.5 \% ; I^{2}=0 \%\right)$ $(P=.49)$ and treatment-related complications $(16 / 81=18.6 \%$; $95 \%$ CI, 10\%-26\%; I ${ }^{2}=0 \%$ versus $15 / 79=16 \%$; 95\% CI, $8 \%-$ $\left.23 \% ; \mathrm{I}^{2}=0 \%\right)(P=.66)$ (On-line Table 8). Although not statistically significant, ischemic complications were higher after treatment between 72 hours and 30 days $(12 / 79=14 \%$; 95\% CI, $7 \%-21 \% ; \mathrm{I}^{2}=0 \%$ ) compared with flow diversion before 72 hours $\left(8 / 81=10 \% ; 95 \%\right.$ CI, 4\%-16\%; $\left.\mathrm{I}^{2}=0 \%\right)(P=.43)$. On the contrary, there was a slightly higher rate of hemorrhagic complications when flow diversion was performed in the early phase $\left(8 / 81=10 \% ; 95 \%\right.$ CI, 5\%-18\%; $\left.I^{2}=0 \%\right)$ compared with flow diversion after 72 hours $\left(3 / 79=4 \%\right.$; 95\% CI, 2\%-13\%; $\left.\mathrm{I}^{2}=0 \%\right)$ $(P=.13)$. Similarly, the rebleeding rate was slightly higher after treatment within 72 hours $\left(3 / 81=4 \%\right.$; 95\% CI, 2\%-10\%; $\mathrm{I}^{2}=$ $0 \%$ versus $1 / 79=1.2 \%$; 95\% CI, $\left.0.8 \%-5 \% ; \mathrm{I}^{2}=0 \%\right)(P=.26)$.

\section{Relationship between Antiplatelet Therapy and Treatment-Related Outcomes}

There were 4 main groups of antiplatelet therapy: dual antiplatelet therapy with clopidogrel (CP) and acetylsalicylic acid (ASA), tirofiban, prasugrel, and abciximab (On-line Table 9). Overall, $67.7 \%(95 \% \mathrm{CI}, 60 \%-73 \%)$ of patients were treated with CP + ASA. The occlusion rates and the treatment-related complications were quite comparable among the different types of antiplatelet therapy. Aneurysm rebleeding was 3\% (95\% CI, 9.6\%$8 \%)$ and $2.8 \%(95 \% \mathrm{CI}, 0.1 \%-15 \%)$ in the group of patients treated with $\mathrm{CP}+\mathrm{ASA}$ and tirofiban, respectively.

\section{Study Heterogeneity}

Substantial heterogeneity was reported in the following outcomes: overall rate of treatment-related complications, occlusion rate of anterior circulation aneurysms, and complication rate of aneurysms treated with a flow-diverter alone.

\section{DISCUSSION}

The aim of the endovascular treatment of ruptured intracranial aneurysms is to give effective protection against aneurysm rerupture while minimizing the complications related to the treatment. While large multicentric studies and meta-analyses have demonstrated the safety and efficacy of flow-diversion treatment of un- ruptured aneurysms, ${ }^{6,31} \mathrm{few}$, small reports described treatmentrelated results of flow-diverter stents in acute SAH. ${ }^{7-26}$ In general, the use of flow diverters in ruptured lesions is controversial and theoretically contraindicated due to the necessity of dual antiplatelet therapy administration. ${ }^{9}$ Pooling the results of 20 studies, our analysis provides more representative data on the angiographic and clinical outcomes after flow-diversion treatment of ruptured intracranial aneurysms.

\section{Angiographic Outcomes}

Due to the high pore density, flow-diverter stents disrupt the flow from the parent artery into the aneurysm, promoting a progressive thrombosis and shrinkage of the lesion. ${ }^{4}$ While only $32 \%$ of the ruptured aneurysms were occluded immediately after treatment, nearly $90 \%$ of the lesions had complete/near-complete occlusion during the 9.6 months of radiologic follow-up. Flow diversion was particularly effective in the treatment of blister and dissecting/fusiform aneurysms, allowing a slightly higher occlusion rate (89\%) compared with saccular lesions (79\%). Aydin et $\mathrm{al}^{7}$ reported complete occlusion of 9 of 10 blood-blister-like aneurysms during 6 months of angiographic follow-up, though only 1 aneurysm presented with near-complete occlusion immediately after the stent deployment. However, a recent series and metaanalysis demonstrated that deconstructive techniques are also an effective treatment option for ruptured dissecting and blister aneurysms. In a meta-analysis of 265 ruptured blisterlike aneurysms, Rouchaud et $\mathrm{al}^{2}$ showed that endovascular deconstructive techniques achieved higher rates of initial and long-term complete occlusion (77\% and $81 \%$ ) compared with reconstructive treatments (33\% and $73 \%$ ), albeit with higher rates of periprocedural ischemic complications.

Given that aneurysm occlusion is a progressive process requiring weeks or months, along with the need for the antiplatelet therapy administration, there is a theoretic risk of rebleeding after flow diversion of ruptured aneurysms. The results of the 1-year follow-up of the International Subarachnoid Aneurysm Trial study $^{32}$ showed $2.7 \%$ rebleeding among 1073 patients treated with endovascular coiling. In our review, rebleeding was higher during the first 72 hours of flow diversion, occurring in $4 \%$ of treated patients ( 1 large fusiform, 1 small, and 3 giant saccular aneurysms) without statistically significant differences between the anterior and posterior circulation. Although rebleeding occurred predominantly among large-giant lesions, treatment of large and giant aneurysms has higher rates of complications regardless of the treatment. ${ }^{33}$ In a previous review of flow-diversion treatment of ruptured intracranial aneurysms, rerupture occurred in approximately $5 \%$ of patients, with $67 \%$ of rebleedings among lesions measuring $>2 \mathrm{~cm} .{ }^{34}$ Series of ruptured aneurysms treated with coiling or stent-assisted coiling showed a rebleeding rate ranging from $2 \%$ to $17 \%^{35,36}$ : Rerupture was higher during the first 3 days, and it was influenced by the degree of aneurysm occlusion and the SAH grade, with a trend toward higher rebleeding after stent-assisted coiling and for larger aneurysms.

Assessing factors related to aneurysm occlusion, we found that patients younger than 60 years of age had a higher occlusion rate compared with the older group ( $90 \%$ versus $76 \%, P=.01$ ). Adeeb et $\mathrm{al}^{37}$ after treatment of 465 intracranial aneurysms with PEDs, 
showed that older age was a significant predictor of incomplete occlusion at last follow-up. Although the exact reasons are currently unknown, the lower occlusion rates in the elderly may be related to a deficiency in the endothelial repair pathway, with incomplete endothelization of the stent. ${ }^{37}$

\section{Treatment-Related Complications}

Based on the literature, the overall rate of complications after coiling of ruptured aneurysms is approximately $12 \%,{ }^{38}$ whereas the rate of thromboembolic and hemorrhagic events after stentassisted coiling in the acute phase is $11 \%$ and $5.5 \%,{ }^{39}$ respectively. In our meta-analysis, flow diversion was associated with $17.8 \%$ complications, which mostly occurred in the periprocedural/early period after treatment, with a $7 \%$ treatment-related morbidity. Most interesting, flow-diversion treatment of acutely ruptured saccular aneurysms was associated with a higher rate $(23 \%)$ of complications compared with dissecting/fusiform and blister aneurysms ( $13 \%$ and 18\%, respectively). Treatment-related complications after coiling and stent-assisted coiling of ruptured saccular lesions are reported close to $12 \%{ }^{38}$ and $16 \%$, respectively. ${ }^{40,41}$ Accordingly, given the possibility of other treatment strategies, flow diversion for acutely ruptured saccular aneurysms should be considered salvage therapy when traditional treatment methods are unfeasible.

Overall, the rates of thromboembolism and hemorrhagic events (intracerebral hemorrhage and vessel perforation) were quite comparable ( $8 \%$ and $7 \%$, respectively). However, hemorrhagic complications were higher when flow diversion was performed during the first 72 hours, whereas ischemic events were more frequent when the treatment was in the subacute phase. The higher rate of hemorrhages in the early period can be related to the loading dose of antiplatelet therapy needed to achieve a platelet inhibition rate high enough to prevent ischemic complications, in combination with additional surgical intracranial procedures, such as ventriculostomy or decompressive craniectomy, usually performed in the early phase of SAH. ${ }^{15}$ Accordingly, $18 \%$ of the reported hemorrhagic complications were ventriculostomy-related bleeding, ${ }^{15,17,22}$ while $30 \%$ were related to aneurysm rerupture, which is generally higher in the first 72 hours. ${ }^{42}$ On the contrary, the higher ischemic rate during the following weeks after SAH can be related to the higher incidence of vasospasm in this period (within 5 and 21 days). ${ }^{43}$ In this setting, passage of a microcatheter/microwire through vasospastic vessels might be associated with a higher risk of vessel dissection or thromboembolic complications caused by the temporary flow reduction in the narrowed arteries. ${ }^{43}$ Despite decades of advances in microsurgical techniques, dissecting and blister aneurysms also remain very challenging lesions for the surgical approach, and many techniques (clipping and clip reconstruction of the arterial wall, wrapping, revascularization plus trapping, and primary suture repair) have been developed. ${ }^{44}$ In a recent surgical series of 17 blister aneurysms, intraoperative rupture was not negligible and occurred in 7 patients (41\%): Direct clipping was possible in $71 \%$ of patients, whereas the other lesions were treated with bypass and trapping or with clip-reinforced wrapping. ${ }^{45}$

Flow diversion in the posterior circulation is associated with a not negligible rate of ischemic complications related to perfora- tors infarcts. We found $27 \%$ complications when the stents were deployed in the posterior circulation, compared with $11.7 \%$ for anterior circulation aneurysms $(P=.004)$. Similarly, in the International Retrospective Study of the Pipeline Embolization Device, the rates of morbidity and mortality after flow-diversion treatment were higher among the posterior circulation (16.5\%) compared with the anterior circulation lesions $(7 \%){ }^{6}$ In addition, considering only the ruptured lesions, morbidity and mortality were significantly higher after the treatment of posterior circulation aneurysms (50\% versus $14 \%){ }^{6}$

Finally, multiple stents were associated with an increased rate (26\%) of complications, compared with treatment with a single device $(10 \%)$. This finding is in accordance with reports in the literature, ${ }^{46}$ and it might be related to the increased metal density of the overlapped multiple stents that promotes platelet aggregation, increasing the ischemic complications.

\section{Antiplatelet Therapy and Treatment-Related Outcomes}

In a meta-analysis of stent-assisted coiling in SAH, Ryu et al ${ }^{39}$ showed that the event rate of ischemic complications varied among the different methods of antiplatelet therapy administration. The standard management of flow diversion of unruptured aneurysms is pretreatment with ASA and CP 5-10 days before the procedure. ${ }^{9}$ However, for the off-label use of flow-diverter stents among ruptured aneurysms, there is no consensus regarding the antiplatelet pretreatment. We found 4 main groups of antiplatelet therapy administration (On-line Table 9). There were no statistically significant differences among the analyzed subgroups of antiplatelet therapy, with an overall complication rate ranging from $17 \%$ to $23 \%$. The most common drugs were CP plus ASA, administered intraoperatively and maintained after treatment $(19.5 \%$ complications and 3\% rebleeding). In 4 studies, ${ }^{9,18,21,25}$ a protocol with tirofiban infusion, a glycoprotein IIb/IIIa inhibitor, was proposed starting immediately after the stent deployment and continuing for 12 hours after the procedure. The authors reported $17 \%$ complications and $2.8 \%$ aneurysm rebleeding. Lozupone et $\mathrm{al}^{17}$ reported a series of 17 patients with ruptured aneurysms treated with flow diversion: Immediately after stent deployment, a bolus dose of $0.25 \mathrm{mg} / \mathrm{kg}$ of abciximab (an irreversible glycoprotein IIb/IIIa inhibitor) was administered, followed by a 12-hour infusion of $0.125 \mathrm{ng} / \mathrm{kg} / \mathrm{min}$. Although there were no rebleeding events, the authors reported $11 \%$ hemorrhagic and $11 \%$ ischemic complications. Finally, only 1 study ${ }^{21}$ described $50 \mathrm{mg}$ of intraoperative prasugrel administration for 9 acutely treated blood-blister aneurysms, reporting similar rates of complications.

\section{Strengths and Limitations}

Our study has limitations. Most of the series are retrospective studies and small single-institution experiences. Details of platelet inhibition after the antiplatelet therapy administration were infrequently specified. Because of the small number of cases in some subgroups of analysis, the comparison among them may not provide sufficient power to show a statistically significant difference among the studied outcomes. However, publication bias was reasonably excluded from the analysis, and this review is currently the largest available, to our knowledge. It does provide a comprehensive summary and statistical analysis of the published data to 
help guide the initial treatment of a selected subgroup of ruptured aneurysms with flow-diverter stents.

\section{CONCLUSIONS}

In our study, flow-diversion treatment of ruptured intracranial aneurysms yielded high rates of long-term angiographic occlusion, with a relatively low rate of aneurysm rebleeding. However, independent of the type of antiplatelet therapy, flow diversion is associated with approximately $18 \%$ treatment-related complications. When simple coiling or microsurgical clipping is not feasible, anterior circulation ruptured aneurysms can be effectively treated with a flow-diversion technique, minimizing the number of stents deployed. Given the $27 \%$ rate of complications, flow diversion for ruptured posterior circulation aneurysms should be considered only in selected cases not amenable to other treatments.

\section{ACKNOWLEDGMENTS}

We thank Professor Beth De Felici for the English revision.

Disclosures: Federico Cagnazzo_UNRELATED: Employment: University of Florence. Pierre-Henri Lefevre-UNRELATED: Payment for Development of Educational Presentations: Medtronic, Stryker, MicroVention, Balt. Vincent Costalat-UNRELATED: Consultancy: Medtronic, Balt, Stryker; Grants/Grants Pending: Medtronic, Stryker, MicroVention*; Payment for Development of Educational Presentations: Medtronic, Stryker. Paolo Perrini-UNRELATED: Employment: University of Pisa, Azienda Ospedaliero Universitaria Pisana, Comments: Consultant Neurosurgeon. *Money paid to the institution.

\section{REFERENCES}

1. Garrett M, Spetzler RF. Surgical treatment of blister-like aneurysms. World Neurosurg 2012;77:76-77 CrossRef Medline

2. Rouchaud A, Brinjikji W, Cloft HJ, et al. Endovascular treatment of ruptured blister-like aneurysms: a systematic review and metaanalysis with focus on deconstructive versus reconstructive and flow-diverter treatments. AJNR Am J Neuroradiol 2015;36:2331-39 CrossRef Medline

3. Awad AJ, Mascitelli JR, Haroun RR, et al. Endovascular management of fusiform aneurysms in the posterior circulation: the era of flow diversion. Neurosurg Focus 2017;42:E14 CrossRef Medline

4. Kallmes DF, Ding YH, Dai D, et al. A new endoluminal, flow-disrupting device for treatment of saccular aneurysms. Stroke 2007;38: 2346-52 CrossRef Medline

5. Kallmes DF, Brinjikji W, Boccardi E, et al. Aneurysm Study of Pipeline in an Observational Registry (ASPIRe). Interv Neurol 2016;5: 89-99 CrossRef Medline

6. Kallmes DF, Hanel R, Lopes D, et al. International retrospective study of the Pipeline embolization device: a multicenter aneurysm treatment study. AJNR Am J Neuroradiol 2015;36:108-15 CrossRef Medline

7. Aydin K, Arat A, Sencer S, et al. Treatment of ruptured blood blisterlike aneurysms with flow diverter SILK stents. J Neurointerv Surg 2015;7:202-09 CrossRef Medline

8. Cerejo R, Bain M, John S, et al. Flow diverter treatment of cerebral blister aneurysms. Neuroradiology 2017;59:1285-90 CrossRef Medline

9. Chalouhi N, Zanaty M, Whiting A, et al. Treatment of ruptured intracranial aneurysms with the Pipeline embolization device. Neurosurgery 2015;76:165-72; discussion 172 CrossRef Medline

10. Chan RS, Mak CH, Wong AK, et al. Use of the Pipeline embolization device to treat recently ruptured dissecting cerebral aneurysms. Interv Neuroradiol 2014;20:436-41 CrossRef Medline

11. Cruz JP, O'Kelly C, Kelly M, et al. Pipeline embolization device in aneurysmal subarachnoid hemorrhage. AJNR Am J Neuroradiol 2013;34:271-76 CrossRef Medline

12. de Barros Faria M, Castro RN, Lundquist J, et al. The role of the
Pipeline embolization device for the treatment of dissecting intracranial aneurysms. AJNR Am J Neuroradiol 2011;32:2192-95 CrossRef Medline

13. Duman E, Coven I, Yildirim E, et al. Endovascular treatment of wide necked ruptured saccular aneurysms with flow-diverter stent. Turk Neurosurg 2017;27:362-67 CrossRef Medline

14. Kulcsár Z, Wetzel SG, Augsburger L, et al. Effect of flow diversion treatment on very small ruptured aneurysms. Neurosurgery 2010;67: 789-93 CrossRef Medline

15. Lin N, Brouillard AM, Keigher KM, et al. Utilization of Pipeline Embolization Device for treatment of ruptured intracranial aneurysms: US multicenter experience. J Neurointerv Surg 2015;7: 808-15 CrossRef Medline

16. Linfante I, Mayich M, Sonig A, et al. Flow diversion with Pipeline Embolic Device as treatment of subarachnoid hemorrhage secondary to blister aneurysms: dual-center experience and review of the literature. J Neurointerv Surg 2017;9:29-33 CrossRef Medline

17. Lozupone E, Piano M, Valvassori L, et al. Flow diverter devices in ruptured intracranial aneurysms: a single-center experience. $J \mathrm{Neu}$ rosurg 2018;128:1037-43 CrossRef Medline

18. Maus V, Mpotsaris A, Dorn F, et al. The use of flow diverter in ruptured, dissecting intracranial aneurysms of the posterior circulation. World Neurosurg 2018;111:e424-33 CrossRef Medline

19. McAuliffe W, Wenderoth JD. Immediate and midterm results following treatment of recently ruptured intracranial aneurysms with the Pipeline embolization device. AJNR Am J Neuroradiol 2012;33: 487-93 CrossRef Medline

20. Möhlenbruch MA, Herweh C, Jestaedt L, et al. The FRED flow-diverter stent for intracranial aneurysms: clinical study to assess safety and efficacy. AJNR Am J Neuroradiol 2015;36:1155-61 CrossRef Medline

21. Parthasarathy R, Gupta V, Gupta A. Safety of Prasugrel loading in ruptured blister like aneurysm treated with a Pipeline device. $\mathrm{Br} J$ Radiol 2018;91:20170476 CrossRef Medline

22. Peschillo S, Caporlingua A, Cannizzaro D, et al. Flow diverter stent treatment for ruptured basilar trunk perforator aneurysms. $J \mathrm{Neu}$ rointerv Surg 2016;8:190-96 CrossRef Medline

23. Peschillo S, Caporlingua A, Resta MC, et al. Endovascular treatment of large and giant carotid aneurysms with flow-diverter stents alone or in combination with coils: a multicenter experience and longterm follow-up. Oper Neurosurg (Hagerstown) 2017;13:492-502 CrossRef Medline

24. Ryan RW, Khan AS, Barco R, et al. Pipeline flow diversion of ruptured blister aneurysms of the supraclinoid carotid artery using a single-device strategy. Neurosurg Focus 2017;42:E11 CrossRef Medline

25. Volker M, Anastasios M, Jan B, et al. Treatment of intracranial aneurysms with the Pipeline Embolization Device only: a single center experience. Neurointervention 2018;13:32-40 CrossRef Medline

26. Yang C, Vadasz A, Szikora I. Treatment of ruptured blood blister aneurysms using primary flow-diverter stenting with considerations for adjunctive coiling: a single-centre experience and literature review. Interv Neuroradiol 2017;23:465-76 CrossRef Medline

27. Moher D, Liberati A, Tetzlaff J, et al. Preferred reporting items for systematic reviews and meta-analyses: the PRISMA statement. Int J Surg 2010;8:336-41 CrossRef Medline

28. Roy D, Milot G, Raymond J. Endovascular treatment of unruptured aneurysms. Stroke 2001;32:1998-2004 CrossRef Medline

29. O’Kelly CJ, Krings T, Fiorella D, et al. A novel grading scale for the angiographic assessment of intracranial aneurysms treated using flow diverting stents. Interv Neuroradiol 2010;16:133-37 CrossRef Medline

30. Wells G, Shea B, O'Connell D, et al. The Newcastle-Ottawa Scale (NOS) for assessing the quality of nonradomized studies in metaanalyses. Ottawa: Ottawa Hospital Research Institute. 2011. http:// www.evidencebasedpublichealth.de/download/Newcastle_Ottawa_ Scale_Pope_Bruce.pdf. Accessed March 28, 2018

31. Brinjikji W, Murad MH, Lanzino G, et al. Endovascular treatment of 
intracranial aneurysms with flow diverters: a meta-analysis. Stroke 2013;44:442-47 CrossRef Medline

32. Molyneux AJ, Kerr RS, Yu LM, et al; International Subarachnoid Aneurysm Trial (ISAT) Collaborative Group. International Subarachnoid Aneurysm Trial (ISAT) of neurosurgical clipping versus endovascular coiling in 2143 patients with ruptured intracranial aneurysms: a randomised comparison of effects on survival, dependency, seizures, rebleeding, subgroups, and aneurysm occlusion. Lancet 2005;366:809-17 CrossRef Medline

33. Cagnazzo F, Mantilla D, Rouchaud A, et al. Endovascular treatment of very large and giant intracranial aneurysms: comparison between reconstructive and deconstructive techniques-a meta-analysis. AJNR Am J Neuroradiol 2018;39:852-58 CrossRef Medline

34. Madaelil TP, Moran CJ, Cross DT 3rd, et al. Flow diversion in ruptured intracranial aneurysms: a meta-analysis. AJNR Am J Neuroradiol 2017;38:590-95 CrossRef Medline

35. White AC, Roark CD, Case DE, et al. Factors associated with rerupture of intracranial aneurysms after endovascular treatment: a retrospective review of 11 years experience at a single institution and review of the literature. J Clin Neurosci 2017;44:53-62 CrossRef Medline

36. Zhao B, Tan X, Yang H, et al. Stent-assisted coiling versus coiling alone of poor-grade ruptured intracranial aneurysms: a multicenter study. J Neurointerv Surg 2017;9:165-68 CrossRef Medline

37. Adeeb N, Moore JM, Wirtz M, et al. Predictors of incomplete occlusion following Pipeline embolization of intracranial aneurysms: is it less effective in older patients? AJNR Am J Neuroradiol 2017;38: 2295-2300 CrossRef Medline

38. Renowden SA, Benes V, Bradley M, et al. Detachable coil embolisation of ruptured intracranial aneurysms: a single center study, a decade experience. Clin Neurol Neurosurg 2009;111:179-88 CrossRef Medline
39. Ryu CW, Park S, Shin HS, et al. Complications in stent-assisted endovascular therapy of ruptured intracranial aneurysms and relevance to antiplatelet administration: a systematic review. AJNR Am J Neuroradiol 2015;36:1682-88 CrossRef Medline

40. Lodi YM, Latorre JG, El-Zammar Z, et al. Stent assisted coiling of the ruptured wide necked intracranial aneurysm. J Neurointerv Surg 2012;4:281-86 CrossRef Medline

41. Amenta PS, Dalyai RT, Kung D, et al. Stent-assisted coiling of widenecked aneurysms in the setting of acute subarachnoid hemorrhage: experience in 65 patients. Neurosurgery 2012;70:1415-29; discussion 1429 CrossRef Medline

42. Guo LM, Zhou HY, Xu JW, et al. Risk factors related to aneurysmal rebleeding. World Neurosurg 2011;76:292-98; discussion 253-54 CrossRef Medline

43. Alaraj A, Wallace A, Mander N, et al. Outcome following symptomatic cerebral vasospasm on presentation in aneurysmal subarachnoid hemorrhage: coiling vs. clipping. World Neurosurg 2010;74: 138-42 CrossRef Medline

44. Kazumata K, Nakayama N, Nakamura T, et al. Changing treatment strategy from clipping to radial artery graft bypass and parent artery sacrifice in patients with ruptured blister-like internal carotid artery aneurysms. Neurosurgery 2014;10(Suppl 1):66-72; discussion 73 CrossRef Medline

45. Owen CM, Montemurro N, Lawton MT. Blister aneurysms of the internal carotid artery: microsurgical results and management strategy. Neurosurgery 2017;80:235-47 CrossRef Medline

46. Brinjikji W, Lanzino G, Cloft HJ, et al. Risk factors for ischemic complications following Pipeline Embolization Device treatment of intracranial aneurysms: results from the IntrePED study. AJNR Am J Neuroradiol 2016;37:1673-78 CrossRef Medline 